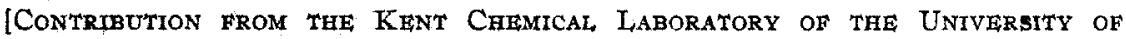
Chicago. 1

\title{
THE SURFACE TENSION AT THE INTERFACE BETWEEN TWO LIQUIDS, AND THE EFFECT OF ACIDS, SALTS AND BASES UPON THE INTERFACIAL TENSION.
}

(SURFACE TENSION III.)

By WILIAM D. HAREINS AND E. C. HUMPHERY.

Received October 22, 1915.

Only a very few accurate measurements have been made upon the interfacial tension between two liquids. Table I gives the new results which have been obtained by the use of the capillary-tube method. The surface tension at the interface water-benzene between $0^{\circ}$ and $40^{\circ}$, is given by the equation

$$
\alpha=35.54(\mathrm{r}-0.056 t) .
$$

The effect of acids, bases, and salts upon interfacial tension is of great interest on account of the importance of this effect in relation to colloids, and therefore it is also of great interest in the study of the physiology of plants and animals. It is well known that when a muscle is at rest it gives a neutral reaction, but when it becomes active the reaction changes to acid. One of the theories of muscular motion is that the production of carbonic, lactic, or other acids is caused by a partial decomposition of chemical compounds in the muscles, that this production of acid causes a change in the electromotive force between the fibrilles and the sarcoplasma, and that this in turn causes a change in the surface tension at the boundary between the two phases which is sufficient to account for the motion of the muscles. Experiments by Haber and Klemenciewicz show that this change of electromotive force, if produced in the system benzene-water, is of no small magnitude, but may be nearly as much as one volt for a small change of concentration from basic to acid near the neutral point. Although the relation between the chemical change and the electromotive force at the interface is thus very simple, the relations with surface tension are very much complicated and obscure. The

Table I.-SURface Tensrons of Water-Liquid X.

Liquid.

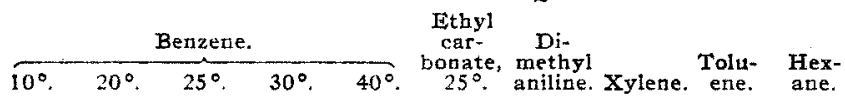

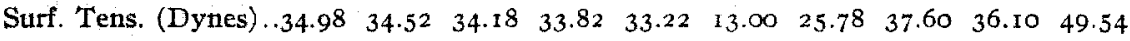

effect of different concentrations of a number of acids, bases, and salts upon the interfacial tension benzene-water is shown by data given in Table II and in Fig. 5. As will be seen from this table, the inorganic acids have only a small effect upon the interfacial tension, but the organic acids have a considerable effect, which increases with the change from formic toward butyric acid. 
The data are given for only one base, ammonium hydroxide. A large number of determinations have been made by the drop-weight method of the effect of highly ionized bases, such as sodium or potassium hydroxide. These bases lower the surface tension slightly, and the results obtained at any one time when the same solution of the base is used, agree well,

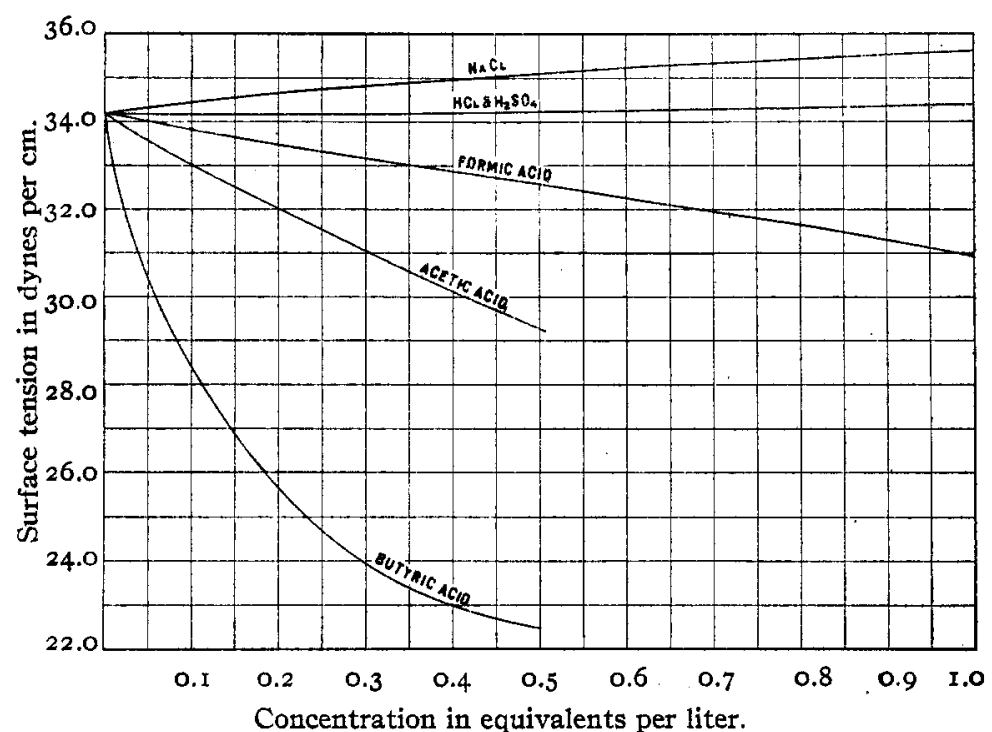

Fig. 5.-Surface tensions at the interface: Aqueous solution-Benzene.

but when different solutions of the base are used, or when the solution has been allowed to stand for some time, the results vary. The capillarytube method as used by von Lerch, ${ }^{3}$ is extremely inaccurate when a highly ionized base is present in the aqueous phase. The work upon the strong bases is still incomplete, and the data obtained will be reserved until later.

TABLE II.-WATER SOLUTYON-BENZENE.

Hydrochloric Acid.
Conc., normal......... 0.000
0.0049
$\begin{array}{llll}0.0098 & 0.0492 & 0.0980 & 0.987\end{array}$
Surface tension ........ 34. I
$34.22 \quad 34.2$
34. $77 \quad 34.23 \quad 34.35$

Sulphuric Acid.

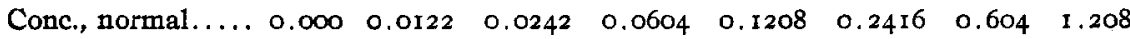
$\begin{array}{llllllll}\text { Surface tension N..34.18 } & 34.16 & 34.17 & 34.15 & 34.15 & 34.18 & 34.29 & 34.39\end{array}$

Sodium Chloride.

$\begin{array}{llllllllll}\text { Conc., normal..... } & 0.000 & 0.0061 & 0.0123 & 0.0614 & 0.1228 & 0.2507 & 0.5205 & 1.034\end{array}$

$\begin{array}{lllllllll}\text { Surface tension... } & 34.18 & 34.21 & 34.25 & 34.33 & 34.49 & 34.75 & 34.99 & 35.67\end{array}$

WATER SOLUTION-BENZENE.

Formic Acid.

Conc., normal..... $\quad 0.00 \quad 0.005 \quad 0.010 \quad 0.0505 \quad 0.101 \quad 0.1935 \quad 0.2525 \quad 0.5275 \quad 0.88 \mathrm{I}$

$\begin{array}{llllllllll}\text { Surface tension.... } & 34.18 & 34.19 & 34.22 & 34.01 & 33.84 & 33.46 & 33.32 & 32.49 & 31.39\end{array}$

1 Ann. Physik, 9, 434-4I (rgor). 
TABLE II (continued).

Acetic Acid.

\begin{tabular}{|c|c|c|c|c|c|c|c|}
\hline Conc., normal... & 0.000 & 0.103 & 0.492 & 0.1034 & \multicolumn{2}{|c|}{0.2068} & 0.508 \\
\hline Surface tension... & $34 \cdot 18$ & $34.0 \mathrm{r}$ & 33.56 & 33.02 & \multicolumn{2}{|c|}{31.99} & 29.24 \\
\hline \multicolumn{8}{|c|}{ Butyric Acid. } \\
\hline Conc., normal.... & 0.000 & 0.010 & 0.020 & 0.100 & 0.200 & 0.300 & 0.500 \\
\hline Surface tension... & $34 \cdot 18$ & 33.01 & 32.17 & 28.37 & 25.63 & 23.89 & 22.45 \\
\hline \multicolumn{8}{|c|}{$\begin{array}{c}\text { WATER SOLUTION-BENZENE. } \\
\text { Ammonium Hydroxide. }\end{array}$} \\
\hline Conc., norm & $\cdots$ & 0.000 & 0.00 & & 0.390 & & 780 \\
\hline Surface tensi & . & 34.18 & 34.00 & & 33.25 & 32.8 & \\
\hline
\end{tabular}

Summary of Papers I, II, and III.

I. The capillary tube method of determining surface tension has been found to be inaccurate whenever aqueous solutions of bases-are used, but the drop-weight method gives accurate results. The difference is due to the fact that in the capillary tube method the surface of the liquid is very small, which makes it very sensitive to the action of impurities. In this method too, there is always the doubt as to the magnitude of the contact angle. The surface of a drop such as is used in drop-weight determinations is, on the other hand, relatively large, and may also be formed very quickly, thus giving a fresh surface, and the theory of the form of the drop gives no indication that the angle of contact is dependent upon the material of the tip if the tip has the proper form.

2. Lohnstein's theory as to the form of the function which must be inserted in the equation giving the surface tension $\alpha$ in terms of the weight of the falling drop (W), has been tested experimentally at the interface between two liquids. This is an ideal method from the standpoint of the theory of the formation of the drop, since in a liquid the drop falls much more slowly than in a gas. Lohnstein calculated the values of the function of $r / a$ in the equation $\alpha=\mathrm{W}[2 \pi r f(r / a)]$. When Lohnstein's values of the function are plotted together with the experimental values as in Fig. I, it is seen that the two curves have exactly the same form, especially at the beginning of the curve where $f(r / a)=\mathrm{I}$, and $r / a=0$. For the larger values of $r / a$ the experimental curve is smooth, while the Lohnstein curve becomes sinuous. This sinuosity is probably the effect of a failure to carry the integrations to a sufficient completeness, which probably resulted from the extreme laboriousness of a complete calculation. Lohnstein's values are not accurate to a greater degree than $4 \%$, so they cannot be used as a basis for accurate work, but his work has the great value that it proves that such laws as that of Tate are only approximations. The experimental curve is undoubtedly more accurate than that of Lohnstein.

3. The surface tension curve is somewhat flat at the bottom, and Tate's 
law assumes that the horizontal tangent is the same as the curve. However, it can be seen from the form of the curve that other tangents can be drawn which approximate the curve as closely as that which is horizontal, so that on this basis laws could be formulated, each as good as that of Tate though not so simple, and as numerous as the tangents to the curve.

4. The correction curve found experimentally is lower than corresponds to the values given by Morgan. This does not mean that Morgan's drop weights are incorrect, but that the values of the surface tension as determined by Ramsay and Shields and other workers by the capillary tube method are too low, since these are the results used by Morgan for the determination of the constant of his equation.

5. The correction factor used in the determination of surface tension by the drop-weight method may be brought very close to the value one by the use of extremely narrow tips, as was done by Antonow, but this is very inadvisable, as his results show, since they vary by $8 \%$.

6. A surface tension apparatus has been devised for the accurate determination of surface tension at a liquid-liquid interface. This apparatus is very simple to set up and easy to use. It can be used for the determination of the surface tension of a single liquid, but the apparatus described in the fourth paper of this series is better suited for this purpose. Another apparatus (Fig. 4), designed for the determination of the surface tension by the capillary tube method, is described. The tube which contained the large meniscus (Fig. ${ }_{4} C$ ) was ro $\mathrm{cm}$. in diameter, and to check the results the large meniscus was made about is centimeters in a glass cylinder. By the use of such large tubes the most common error in capillary height measurements was avoided. The use of a very large lower meniscus, advocated by one of the writers at the Boston meeting of the American Chemical Society, in 1909, and also in this paper as read before the National Academy in December, I9I4, is considered by Richards and Coombs to be responsible for a large part of the increase in the values of the surface tension which they find in their work as compared with the older work of Ramsay and Shields and other workers.

7. The surface tension has been determined at the interfaces between water and the following liquids: benzene, ethyl carbonate, dimethyl aniline, xylene, toluene, and hexane. The results at the interface waterbenzene are about $6 \%$ higher than those obtained formerly by von Lerch or by Antonow. This is interesting in that it is a change in the same direction as that found by Richards and Coombs for the surface tension of single liquids.

8. The effects of acids, bases and salts upon the surface tension at the water-benzene interface, have been studied, and the results are shown graphically in Fig. 5. The effect of bases is much smaller than was found by von Lerch, for example, the new results are in some cases as much 
as $35 \%$ higher than the older ones. The difference in the results is due to a change from the capillary tube to the drop-weight method.

CAICAGO, TIL.

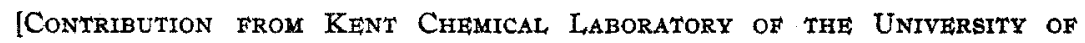
Chicago.]

\section{A SIMPLE APPARATUS FOR THE ACCURATE AND EASY DETER- MINATION OF SURFACE TENSION, WITH A METAL THERMOREGULATOR FOR THE QUICK ADJUSTMENT OF TEMPERATURE.}

BY WILliaM D. HaRting aNd F, E. Brown. 1

Received November $10,1915$.

The importance of the values of the surface tension of a liquid in connection with work in colloidal chemistry, on molecular association, and such technical work as the testing of soap, makes it important to devise apparatus for the determination of the capillary'constant which is at the same time easy to use, and capable of giving very accurate resilts. The aim of the designers of the apparatus here described has been to construct an apparatus as easy or easier to use than the stalagmometer of Traube, or of Donnan, and also so well designed that it will give results of the highest accuracy.

The new apparatus has the following advantages: The surface tension tips are very perfectly ground, and are made from Jena glass, monel metal, or quartz; no cement is used in setting in the tip, so the danger of contamination is eliminated; the apparatus is very rigid; one tip may be taken out, and another one substituted in less than five minutes; the apparatus is already provided with a leveling arrangement which is extremely easy to set, and it is not fragile. Perhaps the greatest advantage over the Morgan ${ }^{2}$ apparatus lies in the substitution of a metal construction for glass, and the consequent elimination of cements, amalgams, linseed oil and plaster of Paris mixtures, and wooden or glass blocks. The setting of these requires a great amount of time, and this is apt to discourage the worker from replacing one surface tension tip by a more suitable one. In the new apparatus the weighing bottles are protected from the water of the thermostat by a nickel plated brass box, fastened to its top by thumb screws, and with a joint made waterproof by a rubber gasket, $\mathrm{R}$ (Figs. I and 2). In the apparatus as described, monel metal stoppers are used but glass stoppers may be substituted for these if a slight change is made in the design, as indicated in the last part of the paper.

1 This is the first of a series of papers on surface tension to be presented to the University of Chicago by F. E. Brown as a dissertation in part fulfilment of the requirements for the $\mathrm{Ph} . \mathrm{D}$. degree.

This Journal, 33, 349 (I911). 